\title{
The effect of nasal provocation with a single-dose allergen on the physical and cognitive performance of patients with ragweed allergy
}

\author{
M Tokodi ${ }^{1}$, E Csábi ${ }^{2}$, Á Kiricsi ${ }^{1}$, E Kollár ${ }^{1}$, AH Molnár ${ }^{3}$, L Rovó $^{1}$, Z Bella ${ }^{1}$ \\ ${ }^{1}$ Department of Oto-Rhino-Laryngology and Head-Neck Surgery, University of Szeged, Szeged, Hungary \\ ${ }^{2}$ Department of Cognitive and Neuropsychology, Institute of Psychology, University of Szeged, Szeged, Hungary \\ ${ }^{3}$ Institute of Physical Education and Sport Sciences, University of Szeged, Szeged, Hungary
}

Received: May 5, 2017

Accepted: November 24, 2017

\begin{abstract}
Purpose: This study aims to compare the impact of active allergic rhinitis on physical and cognitive abilities of trained allergic athletes to untrained allergic patients. Methods: Cognitive, respiratory, and fitness functions were assessed before and after allergen exposure. Participants in both groups were provoked intranasally with ragweed allergen. Results: The group of athletes revealed significantly higher average values in peak inspiratory flow and fitness index before and after provocation. In neuropsychological assessments, athletes performed significantly better after allergen provocation in complex working memory capacity. Due to single acute allergen exposure, the size of the nasal cavity and nasal inspiratory peak flow significantly decreased in both groups. The physical performance of both groups did not change after provocation. Executive functions and complex working memory capacity of athletes significantly improved resulting from provocation. Conclusions: A single-shot allergen in high dose might cause an increase in mental concentration, which was more pronounced in the group of athletes. This study indicates that acute exposure to allergen cannot affect the physical performance and may result in increased mental focus in patients with allergy notwithstanding the declining respiratory functions.
\end{abstract}

Keywords: allergic rhinitis, cognitive function, nasal allergen provocation, physical fitness, respiratory function

\section{Introduction}

Allergic rhinitis is a leading chronic disease with prevalence up to $20 \%$ in developed countries $(10,19)$. Seasonal and perennial allergens have an important role in triggering symptoms that cause persistent or intermittent complaints. Classic symptoms include sneezing, itching, runny, or blocked nose $(5,10)$, which significantly influence the quality of life by interfering with sleep, concentration in study, work, and also leisure activities $(18,20,21)$. Despite the high prevalence of hay fever, no study has so far assessed the effect of symptoms on cognitive functions and physical performance together. This study aims to investigate the acute allergic effects of allergic rhinitis on respiratory parameters, fitness, and cognitive functions. Does regular sport activity modify the influencing effect of allergic symptoms induced by single acute allergen exposure on respiratory, cognitive, and physical outcomes? This open prospective clinical study compares the performance of athletes with allergic rhinitis to non-athletes with allergic rhinitis.

\footnotetext{
Corresponding author: Margaréta Tokodi

Department of Oto-Rhino-Laryngology and Head-Neck Surgery, University of Szeged

Tisza Lajos krt. 111, Szeged 6725, Hungary

Phone: +36 62545 310; Fax: +36 62545 848; E-mail: tokodi.margareta@gmail.com
} 
The relevant literature according to the correlation between sports and allergy shows that physical exercise improves the symptoms of allergic rhinitis, including the decrease in nasal blockage as a characteristic improvement $(1,12,30)$. In addition, sports, such as longdistance running or swimming, may not only decrease airway resistance but also improve endurance and lung capacity $(1,12)$. A large number of studies on the effect of sports on cognitive functions have found that regular physical exercise has a beneficial effect on nervous system functions, thus on a range of cognitive functions including attention, executive functions, short-term memory, decision-making, and locomotor functions $(8,11,16,24,25,31,40)$.

There are also a limited number of studies on the effect of allergic symptoms on cognitive functions often providing conflicting results. Some of these studies have found no changes in certain cognitive functions, such as verbal and visual memory, the speed of information processing (19), and attention processes between healthy people and people with allergy (7, 10). Kremer et al. (19) explained these results by suggesting that people with allergy put more mental effort into carrying out the tasks, which compensates for the decline in certain cognitive areas. In contrast, there are studies that report decreased attention capacity and information processing ability $(15,23,29)$, a functional decline in short-term and verbal memory $(22,38)$, slower decision-making, and locomotor functions in people with allergy compared with non-allergic control groups (23). Wilken et al. (39) compared groups with symptomatic versus non-symptomatic allergy and found that symptoms decrease vigilance, which results in attention capacity and working memory disorders, as well as increased reaction time. According to Blank and Remschmidt (4), allergy affects cognitive functions by the allergy-induced inflammation reaction, which interferes with neural activity and this, in turn, influences the function of the central nervous system and the peripheral nervous system. Marshall et al. (23) concur and add that allergy symptoms decrease concentration and motivation, increase anxiety and emotional distress, and also lead to mental exhaustion and mood disorders. Allergy symptoms together initiate biochemical changes that have a direct effect on the function of the central nervous system. In addition, some authors suggest that it is the antihistamine used for the treatment of allergy that causes cognitive function deficits $(17,32)$, whereas other studies suggest that antihistamine treatments decrease vigilance $(7,34)$.

This study was motivated by the low number and conflicting results of studies published so far and our aim was to assess the effects of allergic rhinitis on breathing parameters, fitness, and cognitive functions in athletes.

\section{Materials and Methods}

We enrolled 35 participants in the study, but due to unpleasant symptoms, several of them did not undertake the tests after nasal provocation. Finally, a total of 14 subjects with ragweed allergy including five women and nine men completed the whole examination and their results were analyzed. The group of athletes (average age: $42.14 \pm 5.98$ years; average time spent in education: $18.57 \pm 4.92$ years) consisted of seven subjects who did regular training at least five times $(7.5 \mathrm{~h})$ a week. The control group also consisted of seven untrained subjects (average age: $42.29 \pm 5.76$ years; average time spent in education: $18.14 \pm 1.67$ years). The two groups were matched in age and level of education. The subjects involved in the study had allergic rhinitis confirmed by specific immunoglobulin E or prick test and showed moderate to medium symptoms to ragweed in the allergy season. Each subject was informed 
about the purpose and the outline of the study, and signed an informed consent. Ethical regulations were adhered throughout the study. The ethics approval of this study is granted by the Regional and Institutional Human Medical Biological Research Ethics Committee, Clinical Research Coordination Center, University of Szeged (ethical license no. 3368, File no. 43/2014).

The study was carried out in a pollen-free period of the year at the Department of Oto-Rhino-Laryngology and Head-Neck Surgery of the University of Szeged. Each participant was tested on two occasions; first at baseline with no symptoms and then, on a second session, immediately after allergen-specific nasal provocation. Nasal provocation was performed using ragweed allergen (Stallergenes, France) at a dose of $0.2 \mathrm{ml}$ of $30 \mathrm{IR} / \mathrm{ml}$ for each nostril. Both sessions took around $90 \mathrm{~min}$ for each subject, and respiratory functions were measured first, followed by neuropsychological functions, and finally fitness indicators.

\section{Assessment of respiratory functions}

Acoustic rhinometry (AR) (GM Instruments, UK) is an objective measurement based on the sound reflection of the nasal cavity. It is a static respiratory function test to assess nasal cavity volumes in the range of $0-7$ (AR vol. 0-7) and 2-5 $\mathrm{cm}^{3}$ (AR vol. 2-5) from the nostrils (3). Dynamic respiratory function tests included nasal inspiratory peak flow [NIPF (L/min)] measurement (Clement Clarke, UK) (27). Lung volume and its changes compared with time [forced expiratory volume in $1 \mathrm{~s}-\mathrm{FEV}_{1}(\mathrm{~L})$ ] and airflow [peak inspiratory flow - PIF (L/s)] were monitored by spirometry (Thor Laboratories, Hungary). From the test values, we could infer the width or stenosis of the airways (35).

\section{Assessment of fitness index}

The Harvard step test (HST), a relatively well-known test in this area, was used for the objective assessment of physical fitness. The test involved the subject stepping up and down a platform at a rate of $120 \mathrm{steps} /$ minute for $5 \mathrm{~min}$. After this exercise had been completed, the subject's pulse rate was measured at $1-1.5,2-2.5$, and $3-3.5 \mathrm{~min}$. The fitness index was calculated using the following equation: time of exercise in seconds $\times 100 /$ sum of pulses $\times 2$. Guiding values are summarized in a standard table (2).

\section{Assessment of cognitive functions}

To map the neuropsychological functions of the brain, we used tests that covered all of its function areas and were able to indicate minor alterations.

Executive functions were assessed using letter and semantic fluency tests, where the participant had to list as many words as possible either beginning with a specified letter (letter fluency) or from a specified category (semantic fluency) in $60 \mathrm{~s}$ (37). In our experiment, in the case of letter fluency, we used letter " $t$ " before the provocation and letter " $\mathrm{k}$ " after the provocation. In case of semantic fluency, we used "animal" category before the provocation and "food products" category after the treatment. We measured the number of correct words, the perseverations, and errors both in letter and semantic fluency tasks.

The verbal component of short-term memory was tested using a digit span test, in which the subjects had to repeat a growing list of numbers in a predefined order (36). Complex working memory capacity was measured by a backward digit span, in which subjects again had to repeat an increasing list of numbers, but this time in reverse order. Each digit span test consisted of four series and the subjects had to repeat at least two of them correctly to proceed to the next span. The shortest span consisted of three items, the longest contained nine items, 
and only the correctly repeated ones were accepted. The short-term verbal and complex memory capacity of the subject was defined as the longest span that the subject could repeat correctly (36). The visual component of the short-term memory was tested using a Corsi block-tapping test, which involves tapping 2-cm-diameter cubes randomly fixed on a black board in the sequence shown by the researcher. Each span consisted of four series and the subject had to repeat at least two of them correctly to proceed to the next span. The shortest span consisted of three items, the longest contained nine items, and only the correctly repeated ones were accepted. The short-term visual span of the subject was defined as the longest span that the subject could repeat correctly (36).

The level of anxiety was assessed using Spielberger's State-Trait Anxiety Inventory (STAI) that measures the level of both state anxiety and trait anxiety. The subjects had to assess on a scale of 1-4 how each statement characterizes them (33).

\section{Statistical analysis}

The SPSS 22.0 Statistics software was used throughout the study. The average values of the two groups were compared using the two-sample $t$-test and the two testing sessions were separately compared in each group using the paired $t$-test. Data are reported as means $\pm \mathrm{SD}$.

\section{Results}

\section{Baseline measurements}

At baseline, there is a significant difference between the trained athlete and the untrained group in the HST (Fig. 1) and PIF values (Table I). No significant differences were found between the two groups for the other respiratory parameters or neuropsychological functions.

\section{Measurements after provocation}

Following nasal provocation, the two groups showed no differences in the parameters of nasal cavity volume in both ranges (Table I). However, there is a significant difference in PIF values in favor of the athlete group. Unsurprisingly the lung capacity results of the athlete group were significantly higher (Table I).

The two groups showed similar results for NIPF, because nasal provocation caused severe swelling of the nasal mucosa that blocked nasal airflow totally in both groups following nasal provocation (Table I).

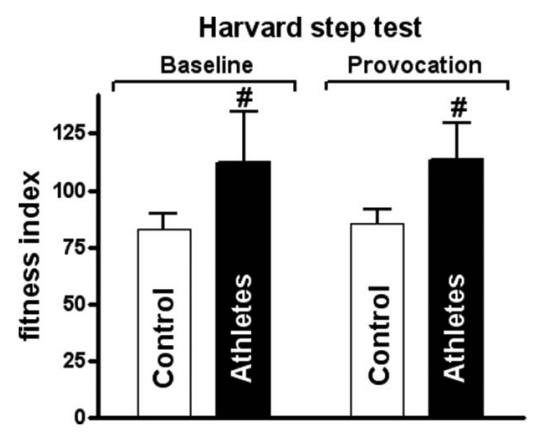

Fig. 1. Fitness index of allergic athletes versus non-athletes based on Harvard step test (HST). \#Significant difference versus the control $(p<0.05)$ 
Table I. Results of respiratory and cognitive tests (mean $\pm \mathrm{SD})$

\begin{tabular}{|l|c|c|c|c|}
\hline & Baseline control & Baseline athletes & $\begin{array}{c}\text { Provocation } \\
\text { control }\end{array}$ & $\begin{array}{c}\text { Provocation } \\
\text { athletes }\end{array}$ \\
\hline AR vol. 2-5 $\left(\mathrm{cm}^{3}\right)$ & $8.96 \pm 3.13$ & $9.29 \pm 2.72$ & $2.46 \pm 1.17^{\mathrm{a}}$ & $3.26 \pm 1.7^{\mathrm{a}}$ \\
\hline AR vol. 0-7 $\left(\mathrm{cm}^{3}\right)$ & $24.32 \pm 5.77$ & $25.61 \pm 6.82$ & $9.85 \pm 2.66^{\mathrm{a}}$ & $13.11 \pm 3.76^{\mathrm{a}}$ \\
\hline NIPF (L/min) & $115.71 \pm 71.08$ & $183.57 \pm 95.51$ & $0.00 \pm 0.00^{\mathrm{a}}$ & $0.00 \pm 0.00^{\mathrm{a}}$ \\
\hline FEV (L) & $3.43 \pm 1.08$ & $4.13 \pm 0.78$ & $3.21 \pm 0.78$ & $4.13 \pm 0.66$ \\
\hline PIF (L/s) & $3.87 \pm 1.54$ & $7.89 \pm 2.69^{\mathrm{b}}$ & $3.53 \pm 1.22$ & $7.24 \pm 1.93^{\mathrm{b}}$ \\
\hline $\begin{array}{l}\text { Letter fluency/all } \\
\text { words (points) }\end{array}$ & $16.43 \pm 4.27$ & $21.43 \pm 8.12$ & $14.00 \pm 6.32$ & $19 \pm 5.19$ \\
\hline $\begin{array}{c}\text { Letter fluency/ } \\
\text { repetition (points) }\end{array}$ & $0.14 \pm 0.37$ & $0.57 \pm 0.97$ & $0.29 \pm 0.48$ & $0.14 \pm 0.37$ \\
\hline $\begin{array}{c}\text { Letter fluency/error } \\
\text { (points) }\end{array}$ & $0.29 \pm 0.48$ & $0.29 \pm 0.48$ & $0.00 \pm 0.00$ & $0.43 \pm 0.53$ \\
\hline STAI/state (points) & $34.14 \pm 4.52$ & $39.43 \pm 14.09$ & $38.86 \pm 9.31$ & $37.71 \pm 6.37$ \\
\hline STAI/trait (points) & $40.57 \pm 8.79$ & $42.33 \pm 5.24$ & $41.71 \pm 5.05$ & $39.33 \pm 7.63$ \\
\hline
\end{tabular}

AR vol. 2-5, nasal cavity volume from 2 to $5 \mathrm{~cm}^{3}$; AR vol. $0-7$, nasal cavity volume from 0 to $7 \mathrm{~cm}^{3}$. AR: acoustic rhinometry; NIPF: nasal inspiratory peak flow; $\mathrm{FEV}_{1}$ : forced expiratory volume in $1 \mathrm{~s}$; PIF: peak inspiratory flow; STAI: Spielberger's State-Trait Anxiety Inventory.

${ }^{a}$ Significant difference versus the baseline $(p<0.05)$.

${ }^{\mathrm{b}}$ Significant difference versus the control $(p<0.05)$

Assessment of physical fitness in the two groups following nasal provocation revealed that the average value of the fitness index is significantly higher in the athlete group (Fig. 1).

No significant differences were found between the two groups in the results of letter fluency tests that measure executive functions. Letter fluency tests revealed a tendential difference in the error rate of the two groups, as athletes made errors while no errors were made in the control group (Table I). Of all tests assessing the components of the working memory, only the results of the backward digit span test (measuring complex working memory capacity) showed a significant difference in favor of the athletes (Fig. 2). However, following nasal provocation, both groups scored the same result on the digit span test that measures verbal short-term memory. The Corsi block-tapping test, which assessed the visual component of short-term memory, also failed to provide significant differences between the two groups (Fig. 2).

STAI test revealed no significant differences between the two groups either for state or trait anxiety levels (Table I).

\section{Performance of the groups before and after provocation}

The athlete group showed significant differences in the values of nasal respiration indicators [AR vol. 2-5; vol. 0-7 (Table I); NIPF (Table I)] measured in the first and second sessions. This indicates that provocation caused nasal congestion. There were no significant differences in lung capacity or fitness parameters between measurements at baseline or after nasal provocation. As for cognitive indicators, significant differences between the two 


\section{Complex working memory tests}

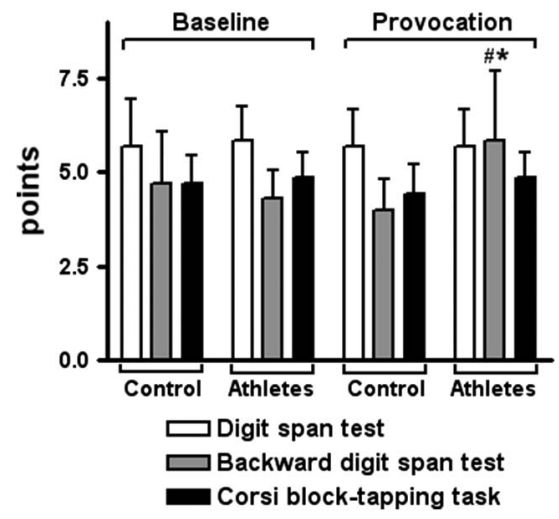

Fig. 2. Results of complex working memory tests of allergic athletes and non-athletes. \#Significant difference versus the control $(p<0.05)$. *Significant difference versus the baseline $(p<0.05)$

sessions were only found for semantic fluency (the total number of all words) (Fig. 3) and the performance of complex working memory (backward digit span) (Fig. 2) with the athletes performing better following provocation in both tests.

Comparison of results from the two sessions showed no additional significant differences for the remaining cognitive function tests or tests for anxiety levels.

Comparison of control group values measured in the first and second sessions revealed significant differences in the same parameters as in the athlete group; namely, in the rate of AR (Table I) in both ranges and NIPF (Table I). There were no significant differences in lung capacity (Table I), fitness index (Fig. 1), or cognitive functions (Table I, Figs 2 and 3).

\section{Discussion}

The aim of this study was to assess the effects of allergic rhinitis on respiration parameters, fitness, and cognitive functions, and also to see whether regular exercise helps develop

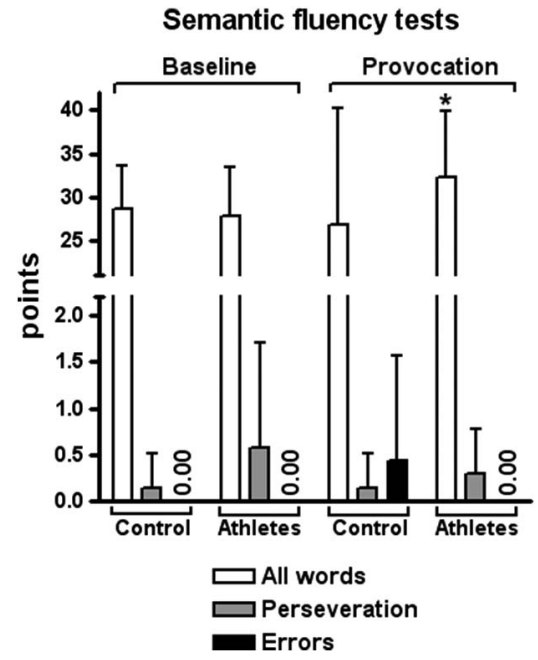

Fig. 3. Results of semantic fluency tests of allergic athletes and non-athletes. *Significant difference versus the baseline $(p<0.05)$ 
resistance against the symptoms. To address these questions, we compared the performance of athletes to non-athletes. The results show a significant difference in fitness indicators and lung capacity between the group of athletes with allergy and the allergic control group before nasal provocation. The athletes performed better in the fitness test and showed higher lung capacity values than the control group. Following nasal provocation, the athletes also showed significantly better lung capacity and fitness indicator values than the control group. In terms of cognitive functions, significant difference was only measured in the performance of the complex working memory with higher scores observed in the group of athletes.

Our results show that the allergic athletes scored higher for fitness indicators and lung capacity in both assessment sessions, which is probably explained by the fact that they are in better physical condition. The two groups showed no differences in cognitive functions before nasal provocation; therefore, this sample does not confirm the claim of Hotting and Roder (13) that regular physical exercise has a beneficial effect on cognitive functions. Our results are similar to Jacobson and Matthaeus's (14) findings, who could not detect differences in executive functions, general intelligence, and the mental processing speed between athletes and non-athletes.

No decline in performance was found in either group following nasal provocation, which is in agreement with studies that also found no differences in cognitive functions between subjects with or without allergic symptoms $(10,19,30)$. Hartgerink-Lutgens et al. (10) explain this by stating the idea that experiencing a decline in the performance of people with allergy is subjective, but this decline cannot be confirmed by objective testing. Our results, however, are in contrast with previous research that indicated a decline in the performance of people with allergy in reaction time, short-term memory performance, and divided attention tasks $(15,22,23,29,38,39)$. However, these studies compared the performance of healthy controls with the performance of those with allergy. The differences in methodology may also account for our different results.

The two measuring sessions unsurprisingly revealed a difference in the level of nasal cavity restriction when the two groups were individually compared. Nasal provocation led to blockage in the nasal cavity, which restricted respiration, but provocation caused no decline in lung capacity. These findings are in contrast with the study of Price et al. (28) who showed that inflammations of upper and lower airways are in close correlation; inflammation of the nose may lead to bronchial hyperresponsiveness and, in turn, a reaction in the lungs may lead to inflammation in the nose (6). In some studies, patients with allergic rhinitis seemed to be free from bronchial hyperresponsiveness, but signs of allergic inflammation were found in the airways in the form of sputum induction.

Our results suggest that the allergic athlete group performed better compared with both the control and to itself following nasal provocation in executive functions and complex working memory tests. This may be explained by findings from previous studies $(4,9,26)$, which have shown that regular exercise correlates with resilience, thus improves stress resistance. This explains why people doing regular exercise tend to perform better under stress. This study involved athletes who are exposed to stress regularly during preparation for international competitions and during competitions (without themselves). Adaptation to such stress may explain the improved physical and cognitive performance following nasal provocation compared with baseline.

In summary, nasal provocation did not significantly influence the cognitive and physical performance of the control group of people with allergy and in the group of allergic athletes, in fact improved results were recorded for certain functions. Disturbing elements caused by 
nasal provocation, such as swollen nasal mucosa, sneezing, and watering eyes did not hinder cognitive functions in people with allergy. One explanation may be the competitive spirit of athletes. In sum, this study indicates that exposure to a single, high dose of allergen may result in increased focus in patients with allergy.

Limitation of this study is the low number of participants. We could include only a few allergic athletes of similar age practicing the same sport. Only these participants undertook the unpleasant symptoms of nasal provocation. Moreover, we should mention that in the real life, there is always a chronic exposure to allergens that might result in impaired psychological well-being and cognitive functioning $(19,23)$.

\section{Acknowledgements}

The authors would like to thank the following: students of the Institute of Psychology, Department of Cognitive and Neuropsychology, University of Szeged, Csaba Csonka - Department of Biochemistry, Faculty of Medicine, University of Szeged.

\section{Abbreviations}

AR vol. 2-5 : nasal cavity volume from 2 to $5 \mathrm{~cm}^{3}$

AR vol. 0-7 : nasal cavity volume from 0 to $7 \mathrm{~cm}^{3}$

AR : acoustic rhinometry

FEV1 : forced expiratory volume in $1 \mathrm{~s}$

HST : Harvard step test

NIPF : nasal inspiratory peak flow

PIF : peak inspiratory flow

STAI : Spielberger's State-Trait Anxiety Inventory

\section{REFERENCES}

1. Alaranta A, Alaranta H, Heliovaara M, Alha P, Palmu P, Helenius I: Allergic rhinitis and pharmacological management in elite athletes. Med. Sci. Sports Exerc. 37, 707-711 (2005)

2. Andrade CH, Cianci RG, Malaguti C, Corso SD: The use of step tests for the assessment of exercise capacity in healthy subjects and in patients with chronic lung disease. J. Bras. Pneumol. 38, 116-124 (2012)

3. Austin CE, Foreman JC: Acoustic rhinometry compared with posterior rhinomanometry in the measurement of histamine- and bradykinin-induced changes in nasal airway patency. Br. J. Clin. Pharmacol. 37, 33-37 (1994)

4. Blank R, Remschmidt R: Hyperkinetic syndrome: the role of allergy among psychological and neurological factors. Eur. Child Adolesc. Psychiatry 3, 220-228 (1994)

5. Borres MP: Allergic rhinitis: More than just a stuffy nose. Acta Paediatr. 98, 1088-1092 (2009)

6. Braunstahl GJ, Kleinjan A, Overbeek SE, Prins JB, Hoogsteden HC, Fokkens WJ: Segmental bronchial provocation induces nasal inflammation in allergic rhinitis patients. Am. J. Respir. Crit. Care Med. 161, 2051-2057 (2000)

7. Burns M, Shanaman JE, Shellenberger $\mathrm{CH}$ : A laboratory study of patients with chronic allergic rhinitis: antihistamine effects on skilled performance. J. Allergy Clin. Immunol. 93, 716-724 (1994)

8. Chmura J, Nazar K, Kaciuba-Uscilko H: Choice reaction time during graded exercise in relation to blood lactate and plasma catecholamine thresholds. Int. J. Sports Med. 15, 172-176 (1994)

9. Fletcher D, Sarkar M: A grounded theory of psychological resistance in Olympic champions. Psychol. Sport Exerc. 13, 669-678 (2012)

10. Hartgerink-Lutgens I, Vermeeren A, Vuurman E, Kremer B: Disturbed cognitive functions after nasal provocation in patients with seasonal allergic rhinitis. Clin. Exp. Allergy 39, 500-508 (2009)

11. Hawkins HL, Kramer AF, Capaldi D: Aging, exercise, and attention. Psychol. Aging 7, 643-653 (1992) 
12. Helenius I, Haahtela T: Allergy and asthma in elite summer sport athletes. J. Allergy Clin. Immunol. 106, 444-452 (2000)

13. Hotting K, Roder B: Beneficial effects of physical exercise on neuroplasticity and cognition. Neurosci. Biobehav. Rev. 37, 2243-2257 (2013)

14. Jacobson J, Matthaeus L: Athletics and executive functioning how athletic participation and sport type correlate with cognitive performance. Psychol. Sport Exerc. 15, 521-527 (2014)

15. Juniper EF, Guyatt GH, Dolovich J: Assessment of quality of life in adolescents with allergic rhinoconjunctivitis: development and testing of a questionnaire for clinical trials. J. Allergy Clin. Immunol. 93, 413-423 (1994)

16. Kashihara K, Maruyama T, Murota M, Nakahara Y: Positive effects of acute and moderate physical exercise on cognitive function. J. Physiol. Anthropol. 28, 155-164 (2009)

17. Kay GG, Berman B, Mockoviak SH, Morris CE, Reeves D, Starbuck V, Sukenik E, Harris AG: Initial and steady-state effects of diphenhydramine and loratadine on sedation, cognition, mood, and psychomotor performance. Arch. Intern. Med. 157, 2350-2356 (1997)

18. Kremer B: Quality of life scales in allergic rhinitis. Curr. Opin. Allergy Clin. Immunol. 4, 171-176 (2004)

19. Kremer B, den Hartog HM, Jolles J: Relationship between allergic rhinitis, disturbed cognitive functions and psychological well-being. Clin. Exp. Allergy 32, 1310-1315 (2002)

20. Laforest L, Bousquet J, Pietri G, Sazonov Kocevar V, Yin D, Pacheco Y, Van Ganse E: Quality of life during pollen season in patients with seasonal allergic rhinitis with or without asthma. Int. Arch. Allergy Immunol. 136, 281-286 (2005)

21. Leynaert B, Neukirch C, Liard R, Bousquet J, Neukirch F: Quality of life in allergic rhinitis and asthma. A population-based study of young adults. Am. J. Respir. Crit. Care Med. 162, 1391-1396 (2000)

22. Marshall PS, Colon EA: Effects of allergy season on mood and cognitive function. Ann. Allergy 71, 251-258 (1993)

23. Marshall PS, O'Hara C, Steinberg P: Effects of seasonal allergic rhinitis on selected cognitive abilities. Ann. Allergy Asthma Immunol. 84, 403-410 (2000)

24. McMorris T, Keen P: Effect of exercise on simple reaction times of recreational athletes. Percept. Mot. Skills. 78, 123-130 (1994)

25. McMorris T, Myers S, MacGillivary WW, Sexsmith JR, Fallowfield J, Graydon J, Forster D: Exercise, plasma catecholamine concentrations and decision-making performance of soccer players on a soccer-specific test. J. Sports Sci. 17, 667-676 (1999)

26. Nezhad MAS, Besharat MA: Relations of resilience and hardiness with sport achievement and mental health in a sample of athletes. Procedia Soc. Behav. Sci. 5, 757-763 (2010)

27. Ottaviano G, Scadding GK, Coles S, Lund VJ: Peak nasal inspiratory flow; normal range in adult population. Rhinology 44, 32-35 (2006)

28. Price DB, Swern A, Tozzi CA, Philip G, Polos P: Effect of montelukast on lung function in asthma patients with allergic rhinitis: analysis from the COMPACT trial. Allergy 61, 737-742 (2006)

29. Reilly MC, Tanner A, Meltzer EO: Work, classroom and activity impairment instruments. Validation studies in allergic rhinitis. Clin. Drug. Investig. 11, 278-288 (1996)

30. Richerson HB, Seebohm PM: Nasal airway response to exercise. J. Allergy 41, 269-284 (1968)

31. Rikli RE, Edwards DJ: Effects of a three-year exercise program on motor function and cognitive processing speed in older women. Res. Q. Exerc. Sport 62, 61-67 (1991)

32. Simons FE, Fraser TG, Reggin JD, Roberts JR, Simons KJ: Adverse central nervous system effects of older antihistamines in children. Pediatr. Allergy Immunol. 7, 22-27 (1996)

33. Sipos K, Sipos N (1983): The development and validation of the Hungarian form of the State-Trait Anxiety Inventory. In: Cross-Cultural Anxiety, eds Spielberger CD, Diaz-Guerrero R, Hemisphere Publishing Corporation, Washington, pp. 27-39

34. Spaeth J, Klimek L, Mosges R: Sedation in allergic rhinitis is caused by the condition and not by antihistamine treatment. Allergy 51, 893-906 (1996)

35. Swart F, Schuurmans MM, Heydenreich JC, Pieper CH, Bolliger CT: Comparison of a new desktop spirometer (Spirospec) with a laboratory spirometer in a respiratory out-patient clinic. Respir. Care 48, 591-595 (2003)

36. Szendi I, Kiss G, Racsmány M, Pléh C, Janka Z (2005): Neuropsychological examination of cognitive function. In: Kortünet vagy kórtünet? Mentális zavarok az id skorban [Symptom of Age or Symptom of Disease? Mental Disorders in Aging], ed Tariska P, Medicina, Budapest, pp. 114-161

37. Tánczos T, Janacsek K, Németh D: The relationship between working memory, executive functions and school performance. Alkalmazott Pszichológia [Appl. Psychol.] 14, 55-75 (2014) 
38. Vuurman EF, van Veggel LM, Uiterwijk MM, Leutner D, O'Hanlon JF: Seasonal allergic rhinitis and antihistamine effects on children's learning. Ann. Allergy 71, 121-126 (1993)

39. Wilken JA, Berkowitz R, Kane R: Decrements in vigilance and cognitive functioning associated with ragweedinduced allergic rhinitis. Ann. Allergy Asthma Immunol. 89, 372-380 (2002)

40. Williams AM, Starkes J (2004): Cognitive expertise and performance in interceptive actions. In: Interceptive Actions in Sport, eds Davids K, Savelsbergh G, Bennett SJ, Kamp JV, Routledge, New York, pp. 40-63 